\title{
Methods and Technologies for Ensuring the Reliability of Excitation of Synchronous Generators of Small Hydroelectric Power Stations in Uzbekistan
}

\author{
Baxtiyor Kenjaev ${ }^{*}$, Daniyar Paluanov ${ }^{1}$, Dilmurat Mamatkulov ${ }^{1}$, and Victoria Romanova $^{2}$ \\ ${ }^{1}$ Tashkent State Technical University, Uzbekistan, Tashkent, 2, Universitet Str. \\ ${ }^{2}$ Trans-Baikal State University, Department of Electric Power Generation and Electrical Engineering, Russia, Chita, 30, Aleksandro- \\ Zavodskaya Str.
}

\begin{abstract}
The paper considers a method for protecting a direct current exciter from remagnetization in transient modes. A schematic diagram of the synchronous generator excitation system with an exciter protection device and a description of its operation are given. The proposed technical solution eliminates the violation of the excitation mode and provides high reliability of uninterrupted operation of synchronous generators of small hydroelectric power stations (HPS) by eliminating the possibility of damage to the device that protects the exciter from demagnetization and remagnetization.
\end{abstract}

\section{Introduction}

Currently, the energy sector in Uzbekistan, as well as in the entire country, is undergoing radical changes in the main trends governing the industry, which radically changes the usual ideas and perceptions about the competitiveness of various types of power plants, fuels and ownership forms in connection with the transition to market relations.

The demand for electric and thermal energy in the sectors of the economy and the population is determined by the level of economic development, energy efficiency and energy saving. These factors are closely interrelated and together form possible scenarios for the socio-economic development of the Republic.

In the short and medium term, thermal and hydraulic power plants will remain the main sources of electricity generation, although in some cases non-traditional energy sources are becoming available, despite their relative high cost. Hydropower currently accounts for $\sim 14.3 \%$ of the total electricity production in the Republic of Uzbekistan.

In accordance with the decree of the President of Uzbekistan dated 30.05.2017 a number of measures are planned to reduce energy intensity, introduce energysaving technologies and systems in the economic and social sectors [1].The main goal of the program is to increase the share of renewable energy sources (RES) in the electricity supply sector, as well as to improve and modernize existing capacities. To do this, it is planned to study and implement new technologies based on world experience. Based on the Decree, a set of measures to ensure energy saving in the economy and social sectors is currently being implemented.

Currently, the available generating capacity of the Republic is $12.9 \mathrm{GW}$, of which [2]:
- TPS-11 thousand. MW or $84.7 \%$;

- HPS-1.85 thousand. MW or $14.3 \%$;

- block stations and isolated stations-more than 133 MW or $1 \%$.

In 2019, the TPS generated $89.6 \%$ of the total electricity generated within the Republic. At the same time, the total capacity of power units operating during the maximum load hours of the unified electric power system was 8.6 thousand MW.

\section{Relevance of the research}

Hydropower is an integral part of the energy base of the Republic's economic sector. The use of hydroelectric resources in combination with organic and nuclear fuels for the production of electric energy creates optimal conditions for providing the country's population with electricity and meeting human needs. Hydroelectric resources belong to RES, currently 42 hydroelectric power stations are operated in the Republic.

Today, in Uzbekistan and abroad, special attention is paid to ensuring the reliability of excitation of synchronous generators of small hydroelectric power stations [3]. During the operation of small hydroelectric power stations, stability in the electric power system is violated, which occurs when the frequency, load, and various electrical equipment damages decrease. An effective method and technology for improving the reliability of electric networks is to regulate the excitation of synchronous generators of small hydroelectric power stations. In the operation of electric machine excitation systems, the most common fault is the lack of excitation or a change in the polarity of the voltage at the exciter armature in the absence of external signs. Since this problem affects the operation of hydroelectric power stations, some facilities are

\footnotetext{
* Corresponding author: kenjaev_1982@mail.ru
} 
decommissioned annually and repaired at high cost under operating conditions. That is why it is necessary to develop optimal technical solutions that ensure uninterrupted operation of synchronous generators of small hydroelectric power stations.

\section{Research materials and methods}

Exciters (main and backup) of synchronous generators of hydroelectric power stations have the disadvantage that in transient modes (sudden short circuit of the generator, self-synchronization, sparking of the exciter brushes, transfer of the excitation from the working to the backup and back, forcing with subsequent disbandment, starting after a long downtime during major repairs, etc.), demagnetization and remagnetization of the exciter can occur without special external signs and preservation of its main characteristics.

Due to the reverse polarity of the magnetic system, the polarity of the voltage at the terminals of the exciter changes, and the arrows of voltmeters and ammeters measuring the parameters of the exciter deviate in the opposite direction.

Fig. 1 shows the directions of currents during normal operation of the exciter after its remagnetization [4-7].
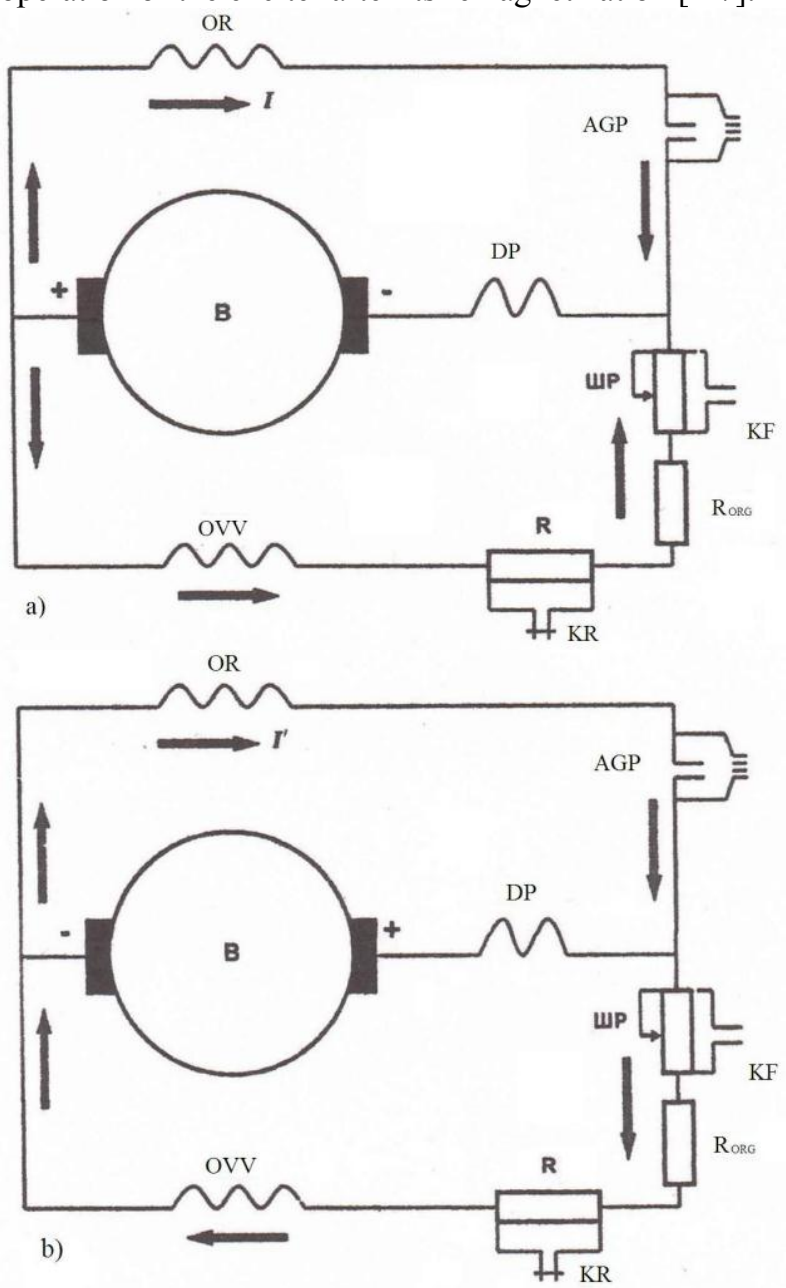

Fig. 1. Direction of currents during normal operation of the exciter.
The process of remagnetization of the exciter in transient modes occurs as follows. When a short circuit occurs in the generator voltage network or in the external network, a free current occurs in the generator rotor, which turns the rotor from the consumer to the current source, and then a reverse current flows through the exciter winding, as shown in Fig. 1B, as a result of this, the exciter is magnetized.

The reason for the remagnetization can be a sparking of the brushes of the exciter. A sudden increase in sparking is equivalent to introducing a large resistance into the armature circuit, as a result of which part of the rotor current branches off into the parallel winding of the exciter and remagnetization occurs.

With a rapid increase in the resistance of the shunt rheostat or the actuation of the de-excitation contactor, the exciter voltage and current in its parallel winding quickly fall. The decreasing field of the generator induces extra currents in the winding of its rotor, which tend to maintain the current value in it, and the rotor is thus exceeded from the consumer to the current source. The current in the parallel winding changes direction and the exciter is magnetized.

On turbo generators, an attempt to switch from working to backup excitation in this case leads to failure of the working and backup excitation systems.

On generators, the magnetization reversal of the exciter is accompanied by loss of excitation, loss of the generator from synchronism, and damage to the stator winding.

The specified disadvantage of the exciter is eliminated if a diode is included in the field winding circuit and protected from overvoltage by a special device, which is a thyristor with a control circuit.

\section{Results and discussions}

The disadvantage of some exciters is the insufficient reliability due to the overvoltage that occurs in the excitation circuit during starts.

The closest in technical essence and the result achieved to the proposed one is the exciter for a synchronous generator, made in the form of a collector DC generator with parallel excitation, containing an armature, an excitation winding and an overvoltage protection device in the form of a diode bridge, in one diagonal of which the excitation winding is included, and the other diagonal of the bridge is connected to the exciter armature.

The disadvantage of this exciter is that when used for a synchronous generator or compensator, it does not provide sufficient reliability of the excitation system, since in transients, when overvoltages occur in the excitation circuit, one of the bridge diodes is damaged (electric breakdown), which leads to loss of excitation and loss of the electric machine from synchronism.

The task of this work is to create an exciter for a synchronous electric machine that provides reliable excitation not only when conditions for remagnetization of the exciter occur, but also when overvoltages occur in the excitation circuit. 
The problem is solved by the fact that a diode is turned on in the exciter for a synchronous generator in the form of a collector DC generator with parallel excitation, containing an armature, an excitation winding and a device for protecting against magnetization reversal. The diode is installed in series with the field winding and is equipped with a surge protection device connected in parallel to it, made in the form of a thyristor, the control electrode of which is connected to its cathode through a zener diode, and through a control circuit made in the form of zener diodes, a resistor and a diode, with its anode.

In addition, the control circuit is made in the form of series-connected zener diodes, resistors and diodes.

For Fig. 2 shows a diagram of the excitation system of a synchronous generator with a device for protecting against magnetization reversal.

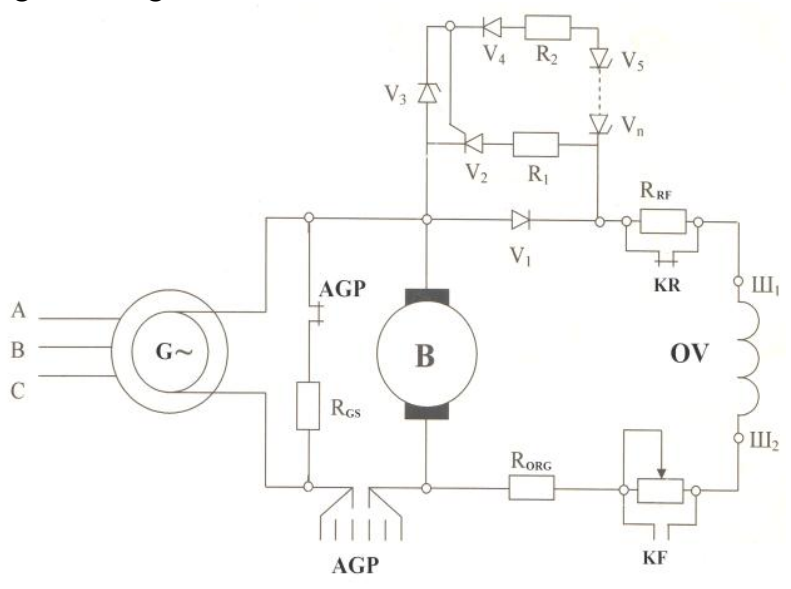

Fig. 2. Synchronous generator excitation system with a device for protecting the exciter from remagnetization:

$\mathrm{V}_{1}$ - VL diode-200 kl. 12; $\mathrm{V}_{2}$ - thyristor T-50 kl. 10; $\mathrm{R}_{1}-$ resistor with a resistance greater than $\mathrm{R}_{\mathrm{kr}}$; $\mathrm{R}_{\mathrm{rf}}-$ deforging resistance.

At normal polarity of the initial EMF ( $\left.E_{\text {rest }}\right)$, created by the magnetic flux of residual magnetism, current flows from the excitation winding, providing selfexcitation of the exciter. The diode does not allow current to flow through the field winding in the opposite direction.

A thyristor connected in parallel to the diode with reverse polarity protects the diode and the field winding from damage during overvoltage on the generator rotor.

The proposed solution has been implemented and successfully operated at a number of HPS in the Republic (for example, the Farkhad HPS, the cascade of the Nizhne-Bozsuyskaya HPS).

As an example, the results of the cascade of the Nizhne-Bozsu HPS are presented. This Cascade, which includes 5 hydroelectric power stations, is the V stage of the cascades of the Chirchik-Bozsuysky water and energy tract-the largest water system of the right-Bank channels of the Chirchik river. The installed capacity of the Cascade Is 50.9 MW. The average annual electricity generation is about 291.2 million $\mathrm{kWh}$.

This Cascade has been in operation for about 75 years. Over the years, a number of repair and restoration works, reconstructions, and replacement of some units have been carried out on the Cascade. However, due to voltage fluctuations during operation, there were problems with the stable operation of synchronous generators of hydroelectric power plants.

According to research data, when connecting the excitation of a synchronous HPP generator in the form of a diagram in figure 2 achieved uninterrupted operation of the synchronous generator and implemented an increase in electricity generation to the population. At the same time, problems that occur when starting and changing the voltage of this Cascade are eliminated, which led to lower operating costs. According to the authors, the implementation of the proposed technological solution for other small HPS in operation will eliminate problems with the excitation of synchronous generators, increase the duration of power generation and ensure the reliability of synchronous generators during operation.

\section{Conclusion}

The conducted research shows that this technical solution eliminates the specified disadvantages of the exciter and provides high reliability of uninterrupted operation of synchronous generators of small hydroelectric power stations by eliminating the possibility of damage to the device that protects the exciter from demagnetization and remagnetization, in the form of a diode. This technical solution should be applied to other small hydroelectric power stations in the Republic, which will increase their productivity.

\section{References}

1. Decree of the President of the Republic of Uzbekistan dated 30.05.2017 "On the program of measures for further development of renewable energy, improving energy efficiency in economic and social sectors for 2017-2021".

2. The Concept of providing the Republic of Uzbekistan with electric energy for 2020-2030.

3. H. Rasulzoda, Researches of the excitation system of synchronous generators with a PID controller. Bulletin of the Chuvash University, №. 3, 123-129 (2017).

4. I. Syromyatnikov, Modes of operation of asynchronous and synchronous motors. M., 240 (1984).

5. V. Venikov, Transient Electromechanical processes in electrical systems. M., 536 (1985).

6. O. Zelenokhat, Development of algorithms for controlling the excitation of synchronous generators for damping the swings of their rotors after large disturbances in the electric power system. M., 170 (2007).

7. V. Shchedrin, Electromagnetic transients in electrical systems. Cheboksary, 416 (2007). 